\title{
FLEXIBLE SPECIALISATION AND WOODWORKING ENTERPRISES IN KENYA AND ZIMBABWE1
}

\section{Arni Sverrisson}

\section{INTRODUCTION}

This article discusses the relevance of the flexible specialisation thesis in the context of existing small and intermediate enterprises. First, the concept is discussed, and a working definition is proposed. Woodworking enterprises in Mutare, Zimbabwe and Nakuru, Kenya are then analysed at the firm level and found to possess several of the characteristics suggested by the idea of flexible specialisation. Next, the enterprise collectives in these two locations are discussed, and found to fall short of the ideal type. By way of conclusion, it is suggested that the flexible specialisation concept is a valuable addition to the ongoing critical development discourse rather than an alternative industrialisation paradigm.

\section{THE FLEXIBLE SPECIALISATION THESIS}

From a Third World perspective the flexible specialisation thesis is an evocative idea rather than an empirical generalisation, and largely untested. However, stating that mass production and the factory system are not necessarily the one and only way of upgrading production facilities, the flexible specialisation thesis opens a range of new perspectives on industrial development.

A particular strength of the flexible specialisation thesis in this context is that it suggests a suitable approach to the study of the complex interrelationships between techniques and the labour process on the one hand, and the prevailing business conditions on the other, in small and intermediate enterprise environments in the Third World.

Further, the potential users of techniques which lend themselves to flexible organisation of production form an identifiable social group. The common interests of this group can be articulated and given an organised expression, in order to influence the actions of governments, and amplify the impact of technological change.

Lastly, opting for improvement through flexible specialisation does not presuppose radical changes in the global order, as pointed out by Hirst and Zeitlin

1 This article is based on material gathered and analysed within a research project, Entrepreneurship and Industrialisation in Kenva, Tanzania and Zimbabwe, conducted at the University of Lund, Sweden. Financial support from the Swedish Agency for Research
(1991). Revolutionary transformation of existing social arrangements in the South are not called for either for this purpose. Indeed, it could be argued that current trends in capital flows and aid to Africa, for example, actually increase the opportunities for existing small and intermediate enterprises (see Havnevik 1987 and Dawson 1990). These conditions could provide a fertile seedbed for progress through the diffusion of general purpose machinery.

\section{A DEFINITION}

In order to facilitate research along these lines, it is necessary to specify in more concrete terms what flexible specialisation implies, and how it relates to the general discussion about small scale industrialisation. In what follows, flexible specialisation will be taken to mean the following:

- a relatively diversified and changeable product range;

- a flexible technological configuration;

- an adjustable form of labour organisation;

- a large share of batch production.

These are attributes of individual firms, which are logically related at that level of analysis. In order to reap the benefits of one, the others must to some extent be present. A diversified product range is for example not feasible if the technical means of adjusting rapidly to changing demand are not available.

In addition it is suggested by the flexible specialisation thesis that enterprise groups can be seen as potential collectives, rather than mere aggregates. The basic prerequisites of such collectives are as follows:

- coexistence within a geographical region of enterprises with a common potential product range, input needs, skills required, and similar technological sophistication levels;

- cooperation between these enterprises and a range of services accessible to them all;

- competition controls and social cohesion expressed in non-economic interaction within the collective;

- a certain degree of permanence and stability in business relations within enterprise clusters.

Cooperation with the Developing Countries (SAREC) is gratefully acknowledged. Thanks are also due to participants at the workshop in Copenhagen, particularly Jesper Rasmussen, as well as Staffan Lindberg, University of Lund, for their useful comments. 
These attributes of enterprise collectives are also logically related. The coexistence of enterprises which share certain characteristics, for example the need for workers with particular skills, calls for services accessible to all, for example vocational training units.

It is important, both for methodological reasons, but also from a theoretical point of view, to distinguish between these two levels of analysis, the enterprise level and the collective level. Flexibility can be the rule at the enterprise level although a fully-fledged collective of flexibly specialised enterprises has not formed as yet. This potential disjunction can therefore be a policy problem and an object of study in its own right (see Schmitz 1989).

Certain aspects considered essential to flexible specialisation by other authors have been left out of this definition, particularly the character of worker's skills, and the presumed innovative behaviour of enterprises in flexibly specialised business environments. It is quite possible that both unskilled and semi-skilled workers are numerous and have an important role to play side by side with broadly skilled workers in an environment otherwise typical of flexible specialisation. It is also possible, even likely, that many proprietors in such environments are survival oriented and imitative. This was the case in the enterprise groups discussed below. As the relation between the more dynamic and innovative participants in African enterprise networks and their survival oriented colleagues is currently inadequately understood, it is in my view somewhat premature to emphasise this aspect of the flexible specialisation idea in development research.

Batch production and a reduced range of variation in technological attributes between enterprises in direct competition have been included, however, in order to facilitate the demarcation of flexible specialisation from other types of technological networks and potential industrialisation trajectories.

Lastly, direct product complementarities between enterprises and niche production have not been included in this definition. It is possible that enterprises concentrate on one or another part of the potential product range. It is also possible that the output of one becomes the input of another. Such phenomena can also be observed in African enterprise environments. However, as noted above, and also by, for example, Schmitz (1989) and King (1991), imitation of standard products plays a large role in concretely existing enterprise environments, in a manner largely predicted by standard diffusion theory (Rogers 1983).

\section{WOODWORKING ENTERPRISES}

Mutare and Nakuru are intermediate towns in Zimbabwe and Kenya. They are well connected to the rest of the countries by road and rail. They are close to commercial forests and plantations, which eliminates bottle-necks in the supply of the basic raw material from the range of problems to be considered. The data summarised and interpreted in the following were collected in repeated interviews with 26 proprietors and managers of woodworking firms in Mutare, and 28 in Nakuru, and the vicinities of these towns, covering in each case an area populated by approximately 400,000 persons. Briefer interviews were also conducted with twice as many persons involved in the processing of wood in various capacities.

The enterprises studied covered a range of technological sophistication from elementary hand tools only to nearto-complete mechanisation of all moments of production. Seasonal or part-time artisan activities were not included. State of the art technologies were not in evidence. The number of persons employed varied, from one to seventy, but a large majority employed between two and five persons.

On the basis of technological sophistication, rather than some other variable, the enterprises can be classified into three categories:

- those using only hand tools;

- those which are partially mechanised;

- those which are almost completely mechanised.

The distribution of the enterprises between the three groups is shown in Table 1 . Within these groups, there were considerable differences, and when a more finely

Table 1: Classification by Technical Sophistication Group

\begin{tabular}{|c|c|c|c|c|}
\hline & Hand Tools & Intermediate & $\begin{array}{l}\text { Largely } \\
\text { Mechanised }\end{array}$ & Total \\
\hline Kenya & 14 & 10 & 4 & 28 \\
\hline Zimbabwe & 14 & 8 & 4 & 26 \\
\hline All & 28 & 18 & 8 & 54 \\
\hline
\end{tabular}


tuned scale was used, the groups merge into each other.

The machinery used was in most cases 'general purpose machinery', i.e. could be used in the production of furniture of different sizes and shapes, and the same description applies to the hand tools used. There are two main reasons for this. Firstly, although the market is large, the share of each enterprise is small and unpredictable, and in principle, each enterprise must be ready to make whatever the prospective customers happen to want, take on building work, etc.

Secondly, when mechanisation is gradual, it is, as it were, inserted into the prevailing craft mode of production. One moment is mechanised, then another, but the other moments continue more or less as before.

The volatility of market shares and diversified demand explain the potential product range for each firm. However, within that range, some firms can select a more or less limited niche(s) and concentrate most of their efforts there. One such niche is expensive hardwood furniture. In addition, it is possible for enterprises to select a few standard designs, and reap the benefits of repetitive production, without going into batch production proper, that is producing several pieces simultaneously.

\section{LABOUR ORGANISATION}

The labour organisation of virtually all the enterprises studied was similar, irrespective of the degree of mechanisation. Each carpenter would work on his own piece, without collaboration with other carpenters, from the beginning until joining was finished. At that stage, either the piece would be sold, or additional sanding done by an apprentice or shop attendant. Perhaps varnish would be applied by a skilled person, often the owner himself, or this would be left to the customer.

The only exceptions to this general rule happened when big orders were placed with short notice. In such cases the proprietor would sometimes organise and lead the work cooperatively. The benefits of cooperation are, in other words, known. These benefits can, however, only be reaped in special circumstances.

Both the underdevelopment of the technical division of labour, and the fact that the incipient specialisation that occurs is concentrated outside the proper domain of the carpenters are circumstances worth a further comment. The prevailing relation between owners and employed carpenters can be characterised as a type of subcontracting in which the carpenters contract to make a specified piece for a specified price. Construing this as piece-rates in the ordinary sense would not quite grasp the importance of this phenomenon, as the contract is for whole pieces, not so many table legs or whatever, and prices are set accordingly. The prices for the pieces vary somewhat, but within a limited range, established through informal communication between carpenters, owners and employees, in the area. The work may be done on the premises of the enterprise, or alternatively, the carpenter can work at home and bring the piece to the workshop.

These arrangements leave the control over actual production to the employees, and creates obvious incentives for them to maximise the pace of work. Simultaneously, working on only one piece at a time severely limits the benefits of planning the work properly. However, in the case of repetitive production following standard designs, the time spent through mistakes, etc. can be reduced considerably.

In consequence, externally oriented activities, such as negotiating contracts, purchasing inputs, discussing price and quality with customers, and controlling the quality of the work, are the main tasks of most proprietors. Detailed organisation, planning or leadership of production activities takes little of their time. Participation in production occurred frequently of course, but the proprietor would then work on complicated pieces for himself, rather than lead the work of others. The exceptions to the prevailing arrangements indicate ways and means of moving beyond the mode of production organisation. They can be summarised as follows:

- exploitation of niches;

- standardised designs;

- limitation of the effective product range;

- repetitive production;

- marketing initiatives;

- vertical integration;

- mechanisation of selected production moments;

- redefining the domain of the carpenters;

- rationalisation of moments outside the piececontracts.

The main conclusion pertaining to technical change is that it is only one of many options open to the expansive proprietor, and not necessarily the most feasible one, considering the risks involved. At the same time, technical change does not have to occur in all enterprises in order to benefit the customers or the collective as a whole.

\section{ENTERPRISE COOPERATION}

It clearly makes sense to see these enterprise groups as collectives. There is considerable, if not total, overlap between customers of the enterprises in the three sophistication groups. They use largely similar raw 
materials and other inputs. Quality differences in the furniture produced, which certainly exist, are gradual and of limited consequence.

However, the aspect which above all constitutes these enterprises as a social totality is their common use of similarly skilled labour. During his career, a carpenter takes on several roles successively, as a pupil, apprentice, trainee, wage-worker, independent, perhaps part-time contractor, working proprietor/manager, etc., but not necessarily all of these or in this order. Person-embodied technical capabilities are in other words a central unifying feature of these enterprise environments.

This is possible because of the relatively limited range of technological sophistication. There are few qualitative differences between the carpentry skills needed in the most sophisticated enterprises and the least sophisticated ones. The variation in technical sophistication itself is gradual, from the simplest to the most complex. Within the low sophistication group, different degrees of hand-tool based sophistication are represented. Within the intermediate group, there are different degrees of partial mechanisation. Within the high sophistication group, there are collections of general purpose machines, rather than dedicated production lines.

Both general social network theory and the more specific flexible specialisation thesis suggest that a degree of stabilisation and cooperation in business environments is a prerequisite of technical advance and dynamic growth (Bijker et al 1987). There are two main forms of cooperation between the enterprises, marketing and technical. In the first instance, proprietors buy and resell other carpenter's products. This phenomenon was found only in Kenya. The entrepreneurs who engaged in this practice had separate, well situated, furniture shops, whereas their workshops were located in not so attractive areas. This compares to the situation of carpenters running workshops located directly in the shopping district, on the one hand, and on the other hand, those with workshops in out-of-the-way locations.

This phenomenon is difficult to distinguish from the subcontracting culture discussed above, and is best seen as an extension of that practice. Two circumstances support this interpretation: all the enterprises concerned were relatively unsophisticated in technical terms, and in all cases this activity was a minor share of total turnover.

A variation on this theme is when proprietors stand in for each other during short absences, or refer customers with special wishes to each other. This was common in both countries. In several cases it was clear that neighbouring carpenters were on good terms with each other, and even joined forces occasionally in order to fulfil large orders given with short notice.

The main form of technical cooperation was the borrowing back and forth of sophisticated and not-socommon hand tools, such as grooving planes, saw sets, etc. This proceeded very much on informal terms. In some cases, a carpenter would even allow another the use of a lathe or a bench saw, without expecting tangible and immediate compensation. However, technical cooperation on a more formal basis also occurred quite frequently, where one carpentry enterprise would, for a price, saw, plane or turn for less fortunate colleagues.

This kind of technical cooperation also extended its branches into the universe of established enterprises. Timber merchants in particular would, for a price, plane, saw and turn according to customers' specifications.

Clustering of the enterprises was an important factor in oiling the wheels of cooperation. In Mutare, the main cluster was located in a market area provided by the municipal authorities, between the centre of town and the main African residential suburb. This cluster was located across the street from the main timber supplier. In Nakuru, carpentry enterprises or their outlets were distributed over a wider area, which can be described as a band of shopping streets winding between the city centre and the main African residential areas. In the outlying villages, carpenters would also concentrate in shopping areas in both countries. Even in decidedly rural areas cooperation would not be totally absent. If at least one carpenter was within reasonable walking distance, tools would be borrowed and lent.

Whether cooperative as pects would be less pronounced in sparsely populated areas is impossible to say from the fieldwork reported here. However, the case of one carpenter in Zimbabwe, who would travel 110 kilometres to obtain cylindrical legs in Mutare, if requested to do so, normally in connection with purchasing trips, suggests that the web of such enterprise relations is not cut off entirely by distance.

\section{COMMERCIAL LINKS}

In contrast, in both countries the established, main street, furniture shops would only exceptionally sell the products of local workshops. The main explanation offered for this by the shop managers was inadequate quality. When prodded about the cases, in which this was manifestly at variance with the facts, unreliable deliveries emerged as another reason.

The carpenters in turn uniformly maintained that the 
price paid by the furniture shops was too low to make business with them worth while. Hence, they would not deal with them except as a last resort, being themselves well placed to attract customers on their own. Large factories in distant towns, in contrast, can compensate for the low prices paid by the shops and the transport costs through economies of scale and better capacity utilisation.

Formal competition controls were not in evidence, but informal agreements on minimum prices between proprietors close to each other were reported. This was rare, however, a circumstance explained by the need to squeeze maximum profit out of each piece. This makes price-cutting an unrealistic strategy in most cases. Rather, the enterprises competed with each other by maintaining reasonable quality standards relative to the means of the customers. Most proprietors also spent considerable time on receiving customers and discussing prices and design with them.

Recapitulating: the carpentry workshops in Nakuru and Mutare are related to other enterprises through various direct business links. The potential exists for a dynamic network to form, involving suppliers of raw material, glue, screws and other inputs, tools and machines, as well as furniture shops, banks and savings societies, and supportive institutions such as training centres, industrial promotion arms of the state and NGOs. Currently, this potential is not fully realised, however. In the environments studied here, relationships characterised by straightforward buying and selling, such as between suppliers of inputs and the carpentry workshops, are well developed. Credit relationships between these actors, or between the existing established credit institutions and most of the carpentry firms were absent. Regular relationships between local carpenters and main-street furniture shops were also non-existent. Technical information flowed largely through informal channels, even to the extent of moving with persons from one enterprise to another.

Existing network relationships can inter alia be analysed by focusing on their temporality: are they of long standing or recently established? Another important aspect is the interaction frequency, expressing strength of the relationship. In the cases discussed here, most relations were of an intermittent character, and the mutual trust involved minimal. That timber merchants are reluctant to provide even short term credit is understandable. It involves small sums to many customers. The risk of default is high, and the torpidity of the judiciary machinery notorious. More surprising was the reluctance expressed by many carpenters to use credit, when offered. This was motivated by the insecurity of their situation.

\section{EXPANSION OR SURVIVAL}

There are basically two ways for enterprises to respond to the volatile character of the enterprise networks. One is adaptive and survival oriented and expressed in expansion and contraction of the activities as demand dictates. The primary expression of this strategy is the casual character of employment discussed above. The other possibility is to facilitate long term expansion through a selection of measures shielding the enterprises from the effects of the extremely competitive situation that prevails. The important point from the perspective of the business environment as a whole is that such measures are options for individual enterprises which thereby advance their positions within the group, and not for all participants in the network.

In Kenya and Zimbabwe the atomisation of Africanowned enterprises contrasts sharply with the tightly knit and exclusive social/business networks of Asians and Europeans respectively. Their relative success in the past is arguably a confirmation of the importance of social, as distinct from economic, cohesion in the constitution and growth of small and intermediate enterprise environments. This notion is also confirmed in the cases discussed here. Positively, in that most mechanising enterprises had also applied some measures to increase and stabilise their market share, negatively, in that most enterprises came up against obstacles which could be traced directly to the relatively atomistic character of enterprise operations. This latter problem was widely recognised by the interviewees.

However, it is not easy to prescribe a solution. Direct external intervention, be it from NGOs, aid projects or the state would in all likelihood meet the same obstacles as hitherto, created by the cultural, educational and political fissures characterising most African societies, and present in Kenya and Zimbabwe as well. However, the most important policy conclusion is that any measures should aim at the strengthening of enterprise clusters and enterprise environments, rather than supporting only enterprises selected by one or another bureaucratic criteria.

\section{FURTHER RESEARCH}

The discussion above shows that many of the ideas contained in the flexible specialisation thesis are useful in interpreting small and intermediate enterprise exeriences in the Third World. The substance of any such interpretation can be contested, of course. This does not, however, detract from the value of the general approach. The issue remains, how can further research along the lines discussed above proceed? 
The first question is whether the term flexible specialisation is suitable. Using terms like collective efficiency, enterprise networks, collective innovation, adaptable enterprise clusters, etc., appears to be more adequate. Such concepts can be defined by a few, logically interdependent, characteristics. Their existence or otherwise can then be verified in an accumulating collection of case studies.

Further, using analytical tools from the kit of diffusionnetwork research, survey questions can be developed on the basis of case studies, and used to obtain evidence from larger populations. In view of the paucity of reliable statistics and the structure of those available, this seems to be a reasonable strategy for going beyond the case study approach.

This kind of research is bound to encounter the same problems as other, substantively defined research fields, where several distinct academic traditions converge. This is among other things reflected in different views of what issues and research questions are central to future work.

From the project reported here, and the sociological perspective applied, two questions appear to be central. One has to do with the volatility of the enterprise networks studied. How can this be accounted for in a satisfactory manner within conceptualisations derived from the network approach, with its emphasis on stable relationships? The second question addresses another problem of the network approach, namely inadequate notions of conflicts, inequalities and hierarchies. How should these issues be treated in the context of enterprise collectives?

From these remarks, as well as the discussion in the first Section, the conclusion follows that a broad definition of the research field should be adopted. One consequence of this standpoint is that flexible specialisation cannot be seen as a strategic alternative all on its own, but rather as an important component of contemporary critical currents within policy oriented development research. In that context, the idea of alternative technological trajectories implied by the flexible specialisation concept can be particularly useful, both as an antidote to petrified industrialisation models and as the basis of an alternative research programme. The idea of innovation as a collective enterprise, also implied by the flexible specialisation thesis, does, in turn, both present an alternative to the myth of the heroic entrepreneur, and guidance to the innovation processes which are already happening.

In addition, it would be of considerable interest to work out properly the possible relations between the flexible specialisation approach and e.g. the Appropriate Technology movement, the current trend to emphasise NGOs as implementing agents in development efforts, ongoing small enterprise development projects, critical discussions of macroeconomic policies and planning, as well as the general private enterprise moods now prevailing in international opinion, which often cast African policy-makers in the role of conservatives.

\section{REFERENCES}

Bijker, W. E., Hughes, T. P. and Pinch, T. (eds.), 1987, The Social Construction of Technology: New Directions in the Sociology and History of Technology, The MIT Press, Cambridge, Massachusetts and London

Dawson, J., 1990, 'The wider context: the importance of the macro-environment for small enterprise development', Small Enterprise Development, Vol 1 No 3: 39-46

Havnevik, K. J., 1987, 'A resource overlooked: crafts and small-scale industries', in J. Boesen, K. J. Havnevik, $\mathrm{J}$. Koponen and R. Odgaard (eds.), Tanzania: Crisis and Struggle for Survival, Scandinavian Institute of African Studies, Uppsala

King, K. and Abuodha, C., 1991, 'The building of industrial society: change and development in Kenya's informal sector 1970-1990', Occasional Paper No 30, Centre of African Studies, Edinburgh University
Hirst, P. and Zeitlin, J., 1991, 'Flexible specialisation versus post-Fordism', in Economy and Society, Vol 20 No 1: 1-55

Rogers, E., 1983, The Diffusion of Innovations, 3rd edition, The Free Press, New York

Schmitz, H., 1989, 'Flexible specialisation: a new paradigm of small-scale industrialisation?', Discussion Paper 261, Institute of Development Studies, Sussex

Sverrisson, A., 1990, 'Entrepreneurship and industrialisation: a case study of carpenters in Mutare, Zimbabwe', Research Policy Studies Discussion Paper No 186, Lund, Sweden

-1992, 'Innovation as a collective enterprise: a case study of carpenters in Nakuru, Kenya', Research Policy Studies Discussion Paper No 189, Lund, Sweden 